\title{
Assessment of sedimentation and useful life of Tehri reservoir using integrated approaches of hydrodynamic modelling, satellite remote sensing and empirical curves
}

\author{
Ayan Anil Garg, Alemayehu A. Shawul* and Sumedha Chakma \\ Department of Civil Engineering, Indian Institute of Technology Delhi, New Delhi 110 016, India
}

The higher rate of sedimentation in reservoirs is one of the main concerns in sustainable reservoir management, which impairs the functional capacity of reservoirs that may lead to various environmental risks. Estimation of sedimentation rate and useful life of a reservoir using appropriate methods is imperative for sustainable management. This paper deals with the computation of sedimentation rate and useful life of Tehri reservoir of Bhagirathi river, in India, using hydrographic survey analysis, Hydrologic Engineering Center's River Analysis System (HEC-RAS) modelling, satellite remote sensing (SRS) technique, and trap efficiency based empirical curve methods. The rate of sedimentation was found as $\mathbf{5 . 3 3}$ million cubic metres (MCM)/year based on hydrographic survey analysis from the data obtained for the years 2005, 2008 and 2013. Likewise, the mean annual rate of sedimentation was estimated to be $5.07 \mathrm{MCM} / \mathrm{year}$ and $5.75 \mathrm{MCM} /$ year based on the HEC-RAS model and SRS techniques respectively. Brune's method and Churchill's method of trap efficiency were found to be inconsistent with the hydrographic survey results. The reservoir can be classified as Type III reservoir with respect to the sediment vertical distribution analysis. Changes in bathymetry obtained in the simulation studies showed that the Bhagirathi river's $28-30 \mathrm{~km}$ reach would be most vulnerable to sedimentation problems. The estimated useful life of Tehri reservoir was found to be in the range of 160-180 years. The SRS technique and hydrodynamic model provided a better fit with the observed data.

Keywords: Empirical curve, HEC-RAS model, reservoir, sedimentation, Tehri reservoir, useful life.

SEDIMENT accumulation in reservoirs is a natural phenomenon, and a matter of great concern for the sustainable dam management where it creates reservoir storage loss impairing the healthy functioning of the reservoir and poses significant safety hazards both at the upstream and downstream of the dams ${ }^{1-3}$. Sedimentation in reservoir

*For correspondence. (e-mail: alemayehu.abate@civil.iitd.ac.in) contributes to a serious threat to the overall safety of the dam, especially in the area of mountainous terrain ${ }^{2}$. It also increases flooding due to delta deposition, accelerates bank and coastal erosion due to the cut-off of sand supply and reduces nutrient delivery to the downstream ecosystem $^{4-6}$. Despite more than eight decades of research on sedimentation, it remains a serious problem being faced by the dam industry ${ }^{7,8}$.

It is estimated that nearly $1 \%$ of the global reservoir storage capacity gets trapped behind the dams every year, in the form of sediments ${ }^{9}$. Reduction in the benefits of the reservoir, such as irrigation and flood control causes a high degree of distress to the population and deteriorates the socio-economic conditions of the region. Presently, there are more than 50,000 large dams constructed (i.e. dams that are more than $15 \mathrm{~m}$ high, or of more than 3 million cubic metres (MCM) storage capacity), and about 350 large reservoirs are currently under construction in China, India, Iran, Turkey, and countries in the Middle East and South-East Asia ${ }^{10}$. India has about 4600 large reservoirs and 100,000 of smaller reservoirs ${ }^{11}$. The total storage capacity of 91 major reservoirs of the country until 2015, was observed to be 157.8 billion cubic meters (BCM), which corresponds to $62 \%$ of the total storage that was created (i.e. 253.4 BCM). The Matatila reservoir on Betwa river in Uttar Pradesh, India, for example, lost $49.7 \%$ of gross capacity between 1956 and 2014 (refs 11, 12). Periodic reservoir capacity assessments are helpful to understand the rate of sedimentation and reduction in storage capacity ${ }^{13}$. Therefore, assessment of sedimentation and subsequent estimation of the useful life of reservoirs is imperative for sustainable water management.

Detailed silt measurement investigations were initiated by Fiock ${ }^{8}$ for the first time, and the general procedure for making reservoir surveys was first described by Eakin ${ }^{14}$, by comparing bathymetric maps of previous records and calculated volume using the standard prismoidal method. The relationship of trap efficiency of the reservoir (ratio of sediment trapped to sediment inflow) with catchment and reservoir characteristics were developed by Brown ${ }^{15}$ and later modified by Churchill ${ }^{16}$ and Brune ${ }^{17}$. Distribution 


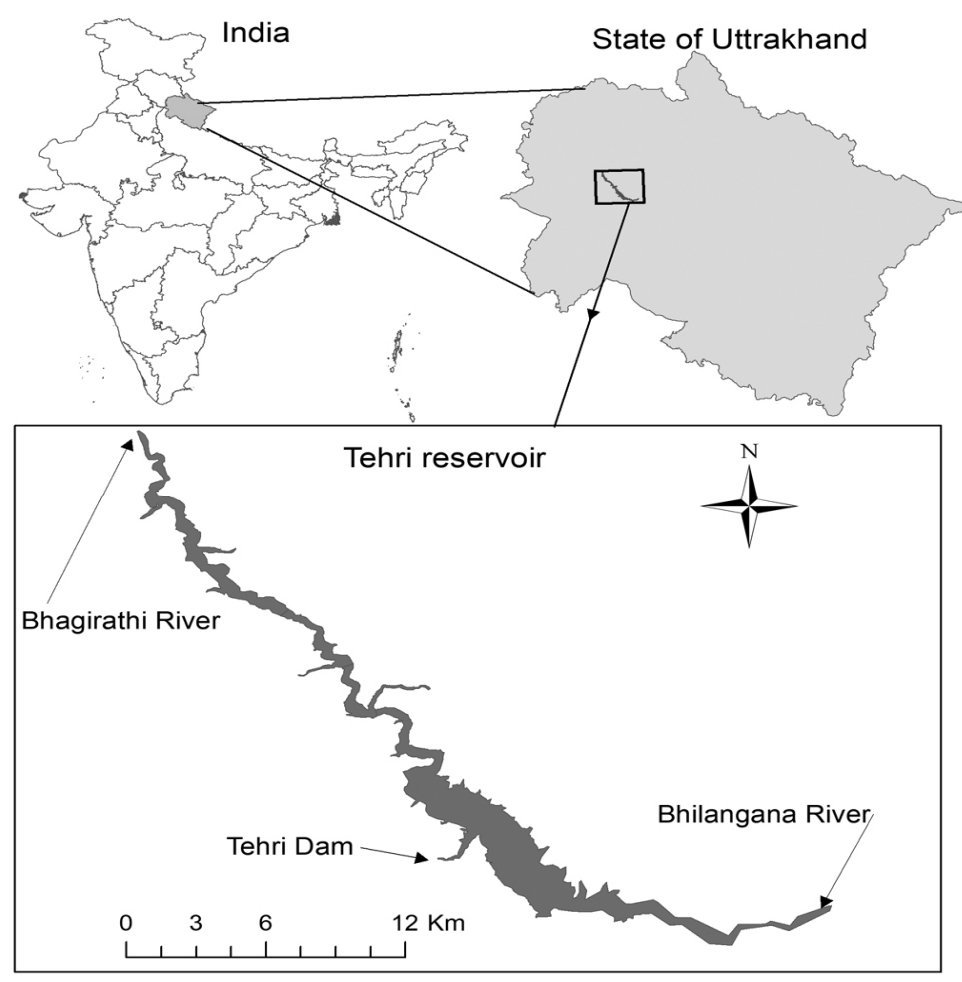

Figure 1. Location map of Tehri reservoir in the state of Uttrakhand, India.

of sediment in the reservoir was studied by Cristofano ${ }^{18}$ by developing area-increment method which was later modified by Borland and Miller ${ }^{19}$, who also developed the empirical area reduction method, using survey data of 30 reservoirs.

Solomonson $^{20}$ and Smith et al. ${ }^{21}$ used satellite remote sensing (SRS) techniques to study the loss of reservoir capacity using water spread method and employed a modified prismoidal method for volume calculations. Several researchers ${ }^{22-24}$ have adopted SRS and GIS techniques for characterization and prioritization of reservoirs at different watersheds. Jagalingam et $a .^{25}$ used SRS techniques to map the bathymetric changes based on Landsat 8 satellite data. SRS and GIS techniques enable fast and accurate estimation of the live storage capacity loss due to reservoir sedimentation ${ }^{26}$; they also reduce the cost and time for reservoir sedimentation studies ${ }^{27}$. SRS-based reservoir sedimentation surveys are based on mapping of the water-spread area using multi-date satellite data which covers the operating level of reservoirs ${ }^{11}$. However, the SRS method of reservoir capacity estimation has certain limitations because it works between the minimum draw-down level (MDDL) and full reservoir level (FRL) where the reservoir operated. Thus, changes can be estimated only in the live capacity of a reservoir. The conventional hydrographic survey techniques are recommended to estimate the capacity below MDDL corresponding to dead storage ${ }^{11,27}$. A realistic determination of the useful life of the reservoir is essential to select suita- ble conservation measures for preserving the existing reservoirs $^{28}$. Therefore, the objective of this study was to estimate the annual sedimentation rates using hydrographic survey analysis, trap efficiency methods (using Brune's and Churchill's curves), Hydrologic Engineering Center's River Analysis System (HEC-RAS) one-dimensional (1D) modelling, and SRS method; and finally to compute the useful life of Tehri reservoir.

\section{Description of the study area and data availability}

Tehri dam is a multi-purpose rock and earth-fill dam on the Bhagirathi river near Tehri in the Uttrakhand state, India. It is located $1.5 \mathrm{~km}$ downstream from the confluence of Bhagirathi, and its tributary Bhilangana, as shown in Figure 1. The dam is presently the ninth tallest in the world and the tallest in India, with a height of $260.5 \mathrm{~m}$. Tehri dam is a multi-purpose dam which is benefiting to the region for irrigation, municipal water supply and generation of $1000 \mathrm{MW}$ of hydroelectricity with an additional pumped storage facility (Tehri-PSP) to generate a total of $2000 \mathrm{MW}$. It was constructed, operated and maintained by the Tehri Hydro Power Complex India Limited (formerly known as Tehri Hydro Development Corporation or THDC).

The two rivers Bhagirathi and Bhilangana form a catchment area of $7511 \mathrm{sq} . \mathrm{km}$. The reservoir is located 


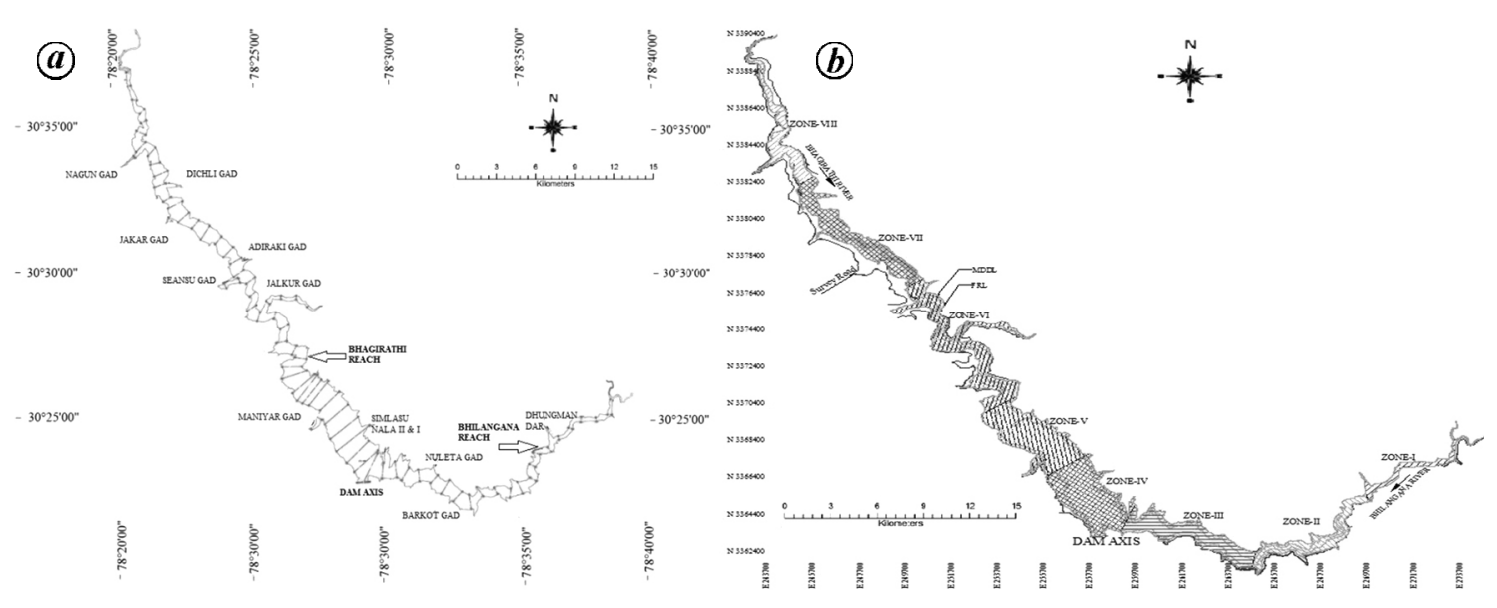

Figure 2. Range-lines used for (a) survey and (b) zones inside the reservoir of Tehri reservoir.

between $30^{\circ} 20^{\prime} \mathrm{N}-30^{\circ} 40^{\prime} \mathrm{N}$ lat. and $78^{\circ} 20^{\prime} \mathrm{E}-78^{\circ} 40^{\prime} \mathrm{E}$ long. It extends up to Dharasu, $44 \mathrm{~km}$ upstream of dam site on Bhagirathi river and up to Ghansyali on Bhilangana river which is about $25 \mathrm{~km}$ upstream of the dam site. The reservoir has a gross storage capacity of $3540 \mathrm{MCM}$ and live storage capacity of $2615 \mathrm{MCM}$ between the MDDL (elevation level (EL) - $740 \mathrm{~m}$ amsl)) and FRL (elevation level $-830 \mathrm{~m}$ amsl). The reservoir at FRL has a surface spread area of 42 sq. $\mathrm{km}$ and the zero elevation near the dam was $620 \mathrm{~m}$ amsl in 2005. The range-line survey was performed by THDC using echosounding technique in 2008 and 2013, and the discharge and water elevation data are available from 1 April 2006 to 30 June 2014. The two surveys were done at each range-line $1 \mathrm{~km}$ apart, as shown in Figure $2 a$, and each cross-section at $30 \mathrm{~m}$ interval. Sediment sampling data was collected from Central Water Commission of India (CWC), Ganga Basin Water Resources Organisation for the period 1973-92 using samplers at Tehri zero point. The mean annual inflow into the reservoir was recorded as $5139.03 \mathrm{MCM}$, and the mean density of sediments inside the Tehri reservoir was found as 1.4 tonnes $\mathrm{m}^{-3}$ (ref. 29).

\section{Materials and methods}

\section{Hydrographic survey method}

The longitudinal sections (or $L$-sections) and crosssections (or $X$-section) were obtained by plotting the hydrographic survey data for rivers Bhilangana and Bhagirathi at various sections in the reservoir. The area of the cross-section at each range-line and submerged area at a fixed interval of elevation were estimated with the help of trapezoidal formula. The volume computations were done using end-area-length method from the area at each cross-section. Revised elevation-areacapacity curve was then plotted, and finally, the annual loss of storage capacity (or annual average rate of siltation) and corresponding useful life of the reservoir were estimated.

The reservoir was then classified by the depth-capacity curve on a $\log -\log$ scale with the calculation of inverse slope or ' $M$ ' given by Borland and Miller' ${ }^{19}$. Using the corresponding storage design curves and area design curves for the type of reservoir, new zero elevation (NZE) (i.e. the raised bed level due to progressive accumulation of sediment) was estimated based on empirical area reduction method ${ }^{19}$ to understand the sediment distribution pattern in the reservoir. Zonal distribution studies were also undertaken by dividing the reservoir into eight zones, as shown in Figure $2 b$, and for each zone, loss of capacity was calculated using end area trapezoidal method. Zones I, II and III were covered by Bhilangana river which started from the entry of the river into the reservoir (25 km to $3 \mathrm{~km}$ reaches); zone IV was the zone of confluence of Bhagirathi and Bhilangana rivers (from $3 \mathrm{~km}$ Bhilangana reach to $5 \mathrm{~km}$ Bhagirathi reach); zones V-VIII were covered by Bhagirathi river $(5 \mathrm{~km}$ to $44.8 \mathrm{~km}$ reaches) up to the entry point.

\section{Empirical curve method}

Brune's trap efficiency method and the Churchill's empirical curve method were used for estimating the reservoir siltation. The trap efficiency method utilizes the capacity to inflow ratio $(\mathrm{C} / \mathrm{I})$ and estimate the annual rate of siltation. The curve was derived from a record of 44 normally ponded reservoirs in USA by Brune ${ }^{17}$ where C/I ratio was recommended in the range of $\varepsilon 0.0016$ to 4.65 . A more complex relation of trap efficiency was given by Churchill $^{16}$, which relates release efficiency (i.e. 1 - trap efficiency) with sedimentation index (SI). SI was denoted as the ratio of average retention time (i.e. C/I) to mean flow velocity for estimating the annual rate of siltation to the corresponding capacities. 


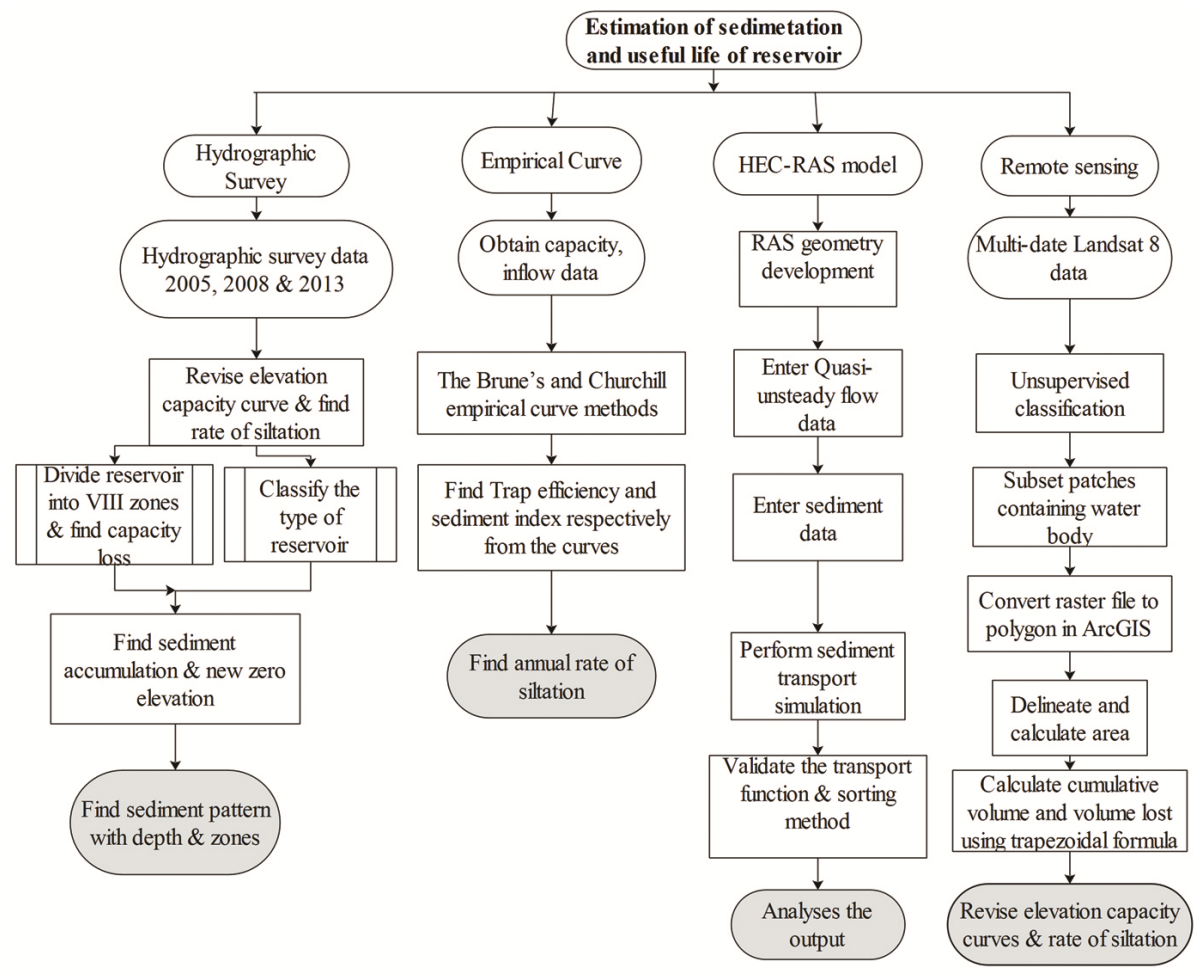

Figure 3. Summarized procedures of the study.

\section{HEC-RAS hydrodynamic model}

The hydrodynamic model was constructed using HECRAS 4.1 developed by the US Army Corps of Engineers (USACE). Hydrographic survey data, water discharge data, sediment discharge corresponding to total capacity lost during 2005-2013, grain size distribution curve, and gate opening data as provided by THDC were used as input to the HEC-RAS model. AutoCAD-Civil 3D 2013 was used for studying the plans provided by THDC and extracted the geometrical data of the Tehri dam reservoir, which was used in HEC-RAS to estimate bathymetric changes.

The standard procedures presented in the HEC-RAS software manual were used for calculation of water surface profiles, as shown in Figure 3. Since the flow was subcritical, HEC-RAS iteratively calculated the water surface profile and energy grade line, beginning with the most downstream cross-section. To start the iterative procedure, a known boundary condition was defined which included the following: (a) Known water surface elevation; (b) Critical depth; (c) Normal depth; and (d) Rating curve of flow at gauged location ${ }^{30}$. HEC-RAS 4.1 consists of several transport functions to calculate the transport rate. The transport of sediment takes place as per the input transport equations, and the subsequent changes of the bed are based on sediment mass balance equation. The governing equations are indicated from eqs (1)-(6), and the detailed background theory of the model is presented in the HEC-RAS manual ${ }^{31}$.

$$
\begin{aligned}
& Q=V_{1} A_{1}=V_{2} A_{2}, \\
& \eta_{2}+y_{2}+\frac{a_{2} V_{2}^{2}}{2 g}=\eta_{1}+y_{1}+\frac{a_{1} V_{1}^{2}}{2 g}+h_{e}, \\
& Q=K S_{f}^{1 / 2}, \\
& (1-\lambda p) \frac{\partial \eta}{\partial t}=-\frac{\partial q_{t}}{\partial x}, \\
& \frac{\partial y}{\partial t}+\frac{\partial v y}{\partial x}=0, \\
& \frac{\partial v y}{\partial t}+\frac{\partial v^{2} y}{\partial x}=-\frac{1}{2} g \frac{\partial y^{2}}{\partial x}-g y \frac{\partial \eta}{\partial x}-\frac{\tau_{b}}{\rho},
\end{aligned}
$$

where $Q$ is the water discharge (cumecs), $x$ the stream wise coordinate $(\mathrm{m}), y$ the elevation of water surface with respect to bed (m), $t$ the time (sec), $\eta=\eta(x, t)=$ bed elevation $(\mathrm{m}), S_{0}=-\partial \eta / \partial x=$ bed slope, $S_{f}=$ energy gradient slope $=(Q / K)^{2}, S_{\mathrm{w}}=$ water surface slope $=\mathrm{d} y / \mathrm{d} x, q_{t}$ the total bed material sediment transport rate or volume flux per unit width $\left(\mathrm{m}^{2} / \mathrm{sec}\right)$ (or $\left.Q_{5} / B\right), \lambda_{p}$ the porosity of bed deposit of sediment, $v$ the velocity (depth averaged) $(\mathrm{m} / \mathrm{sec}), A$ the cross-section area $\left(\mathrm{m}^{2}\right), K$ the average conveyance factor $=R^{2 / 3} A / N, N$ the Manning's coefficient, $h_{e}=$ head loss $=S_{\mathrm{f}} d x(\mathrm{~m}), \tau_{b}$ the boundary shear stress at bed $\left(\mathrm{N} / \mathrm{m}^{2}\right), g$ gravitational acceleration $\left(\mathrm{m} / \mathrm{sec}^{2}\right)$ and $\rho$ is density of water $\left(\mathrm{kg} / \mathrm{m}^{2}\right)$. 


\section{HEC-RAS model setup}

The reservoir cross-sections were prepared based on the survey data for the year 2008 and 2013 along with sediment corresponding to an average loss in the reservoir capacity, and average quarterly discharge data for both Bhagirathi and Bhilangana rivers. In addition, the reservoir water elevations with gate opening data were used as input for the model. Since the model was proposed to run for 100 years, the quarterly average of the discharge provided by THDC was computed and repeated in the same cycle up to 100 years. The value of Manning's coefficient $n=0.045$ (ref. 32), which was obtained from THDC, was used for both rivers in the model, and normal depth with friction slope of 0.01 was assumed for downstream reach. Moreover, the grain size distribution curve was obtained from the sampling data, which was used as input data in the model. Ackers and White ${ }^{33}$ method was used for sediment transport, as it was found to be suitable for uniformly graded sand and gravel. The method is based on a total load function that calculates transport capacity rate $\left(G_{\mathrm{s}}\right)$ using three dimensionless parameters, viz. dimensionless mobility index $\left(F_{\mathrm{gr}}\right)$, dimensionless sediment diameter $\left(d_{\mathrm{gr}}\right)$ and dimensionless sediment transport parameter $\left(G_{\mathrm{gr}}\right)^{29}$. Subsequently, the continuity equation compares the transport capacity to the inflowing load for each grain class at a different time step and if the capacity exceeds the supply (or sediment discharge $Q_{\mathrm{s}}$ ), a deficit is computed (i.e. erosion will take place). Again, if the supply exceeds the capacity, the control volume will have a surplus of the grain class (i.e. the deposition will take place).

\section{Validation of the model}

To validate the model, a geometry file with the post-2008 survey was prepared, and average discharge data observed at the site was run for five years with the observed sediment data, and the loss of capacity was computed by the hydrographic survey. The actual observed reservoir level was maintained throughout the reaches, and siltation rates were compared. The model was then run for 100 years taking 2015 cross-section data and base year as 1 April 2014. Invert changes, mass changes along $X$-sections and $L$-sections denoting the deposition and then its pattern inside the reservoir was plotted.

\section{SRS method}

Multi-temporal Landsat 8 OLI (Operational Land Imager) satellite images were obtained from Earth Explorer website of United States Geological Survey (USGS; https:// earthexplorer.usgs.gov/), for the year 2013, and path 146 - row 39. The Landsat 8 OLI images consisted of nine spectral bands with a spatial resolution of $30 \mathrm{~m}$, band 1 to
7 and 9 had a spatial resolution of $30 \mathrm{~m}$, band 8 (panchromatic) $15 \mathrm{~m}$ spatial resolution, and the thermal bands 10 and 11 had 100 m resolution. In Landsat 8, bands 5, 4, 3 represent colour infrared; bands 4, 3, 2 represent natural colour; and bands 6,5,4 represent false-colour composites $(\mathrm{FCC})^{34}$. The corresponding wavelength ranges were used to delineate shoreline and estimate water spread area using ArcGIS 10.1. Band 8 (panchromatic) was also used to sharpen the shoreline definition to classify the water body using ERDAS - Imagine by Intergraph. The five bands obtained from cloud-free images of Landsat 8 were stacked and converted to FCC for unsupervised classification of water body pixels. The pixels in the imagery comprised of a numerical value, which represented a spectral signature called digital number (DN). If $\mathrm{DN}_{\mathrm{NIR}} \ll$ $\mathrm{DN}_{\mathrm{RED}}+\mathrm{DN}_{\mathrm{GREEN}}$, then it would be classified as water, otherwise not. Even if the water depth is quite shallow, the increased absorption in band 5 restricts the DN value to be less than bands 4 and 3. If the soil is exposed (possibly saturated) at the surface, the reflectance would be as per the signatures of the soil, which would increase with a wavelength in this spectral range ${ }^{26}$. After classifying these FCCs and delineating water body using ERDASImagine, the images were georeferenced to WGS 84 (world geodetic system 1984) and analysed in ArcGIS for water surface area computations. Loss of capacity and rate of siltation were computed using a modified prismoidal formula ${ }^{35}$. The summarized procedures of all the four methods of estimating sedimentation and useful life of the reservoir are presented in Figure 3.

\section{Results and discussion}

\section{Hydrographic survey}

The hydrographic data of the year 2008 and 2013 were analysed to revise the elevation-area-capacity curve to determine sediment distribution pattern and to find vulnerable zones of sediment deposition. The elevationarea calculation for the reservoir indicated that the submerged area of the reservoir at FRL $(830 \mathrm{~m})$ was 41.9 sq. $\mathrm{km}$ in the year 2013 , compared to $42.6 \mathrm{sq} . \mathrm{km}$ in 2008 , and 43.3 sq. $\mathrm{km}$ in 2005 according to THDC. Similarly, the elevation-volume calculation of the reservoir was observed to reduce the capacities of the reservoir at MDDL, FRL, and at an elevation of $840 \mathrm{~m}$, and found to be 907.5 MCM, 3505.8 MCM, and 3973.3 MCM respectively. It was observed from Table 1 that the overall reduction rate of the inactive storage capacity, live storage capacity, gross storage capacity, and flood-area storage capacity of the Tehri reservoir between 2005 and 2013 were $1.095 \mathrm{MCM} /$ year, 4.23 MCM/year, 5.33 MCM/year and $2.70 \mathrm{MCM} /$ year respectively. Decrease in the inactive storage capacity, live storage capacity, gross storage capacity and flood-area storage capacity can have an 
Table 1. Reduction in reservoir capacity

\begin{tabular}{|c|c|c|c|c|c|c|c|c|c|c|c|c|}
\hline \multirow[b]{2}{*}{ Time period } & \multicolumn{3}{|c|}{ Inactive capacity } & \multicolumn{3}{|c|}{ Live capacity } & \multicolumn{3}{|c|}{ Gross capacity } & \multicolumn{3}{|c|}{ Flood-area capacity } \\
\hline & MCM & $\%$ & MCM/year & MCM & $\%$ & MCM/year & MCM & $\%$ & MCM/year & MCM & $\%$ & $\mathrm{MCM} /$ year \\
\hline $2005-2008$ & 5.53 & 0.6 & 1.84 & 15.48 & 0.59 & 5.16 & 21.01 & 0.59 & 7.0 & 18.7 & 0.47 & 6.23 \\
\hline $2008-2013$ & 3.23 & 0.35 & 0.64 & 18.42 & 0.7 & 3.68 & 21.65 & 0.61 & 4.33 & 2.92 & 0.73 & 0.58 \\
\hline $2005-2013$ & 8.76 & 0.96 & 1.095 & 33.90 & 1.3 & 4.23 & 42.66 & 1.2 & 5.33 & 21.62 & 0.54 & 2.70 \\
\hline
\end{tabular}

MCM, Million cubic meters.

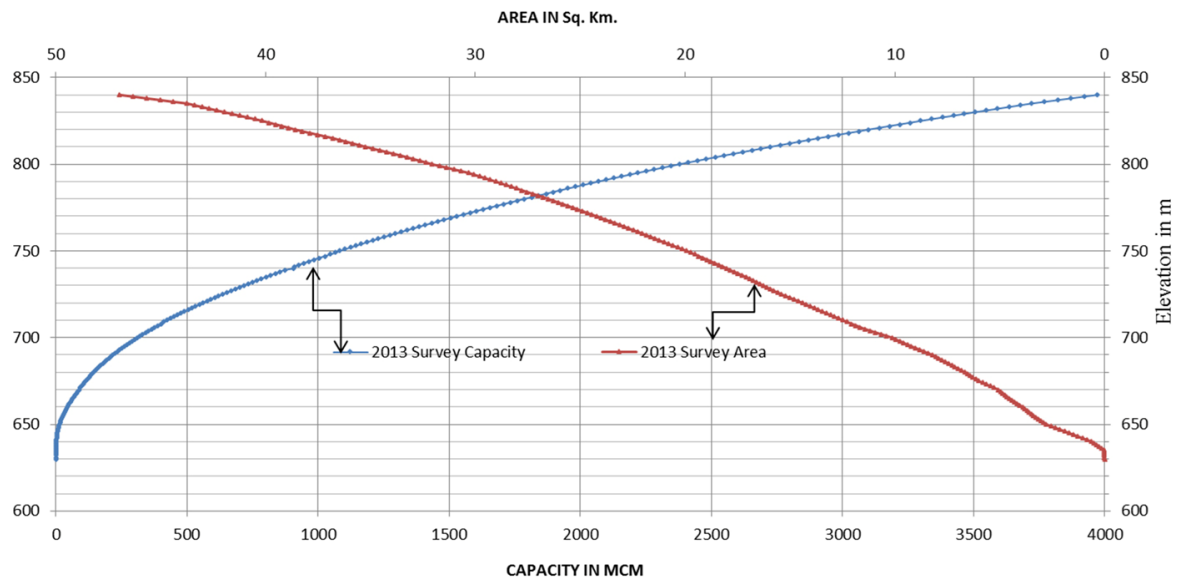

Figure 4. Elevation-area-capacity curve of Tehri in the year 2013 .

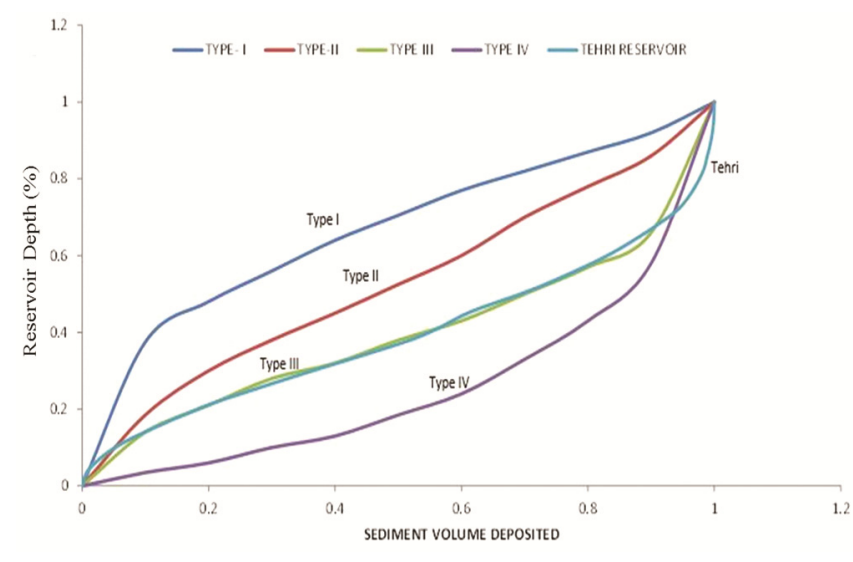

Figure 5. Classification of Tehri reservoir as per United States Bureau of Reclamation (USBR) - Borland and Miller ${ }^{19}$.

undesirable effect on the hydroelectric power generation, irrigation facilities and other related uses of the reservoir.

The observed annual loss of gross capacity was found to be $0.15 \%$, which indicated insignificant losses. This was because of low silt content due to pristine water flow from the Himalayas, along with rocky terrain, and cascading to the main reservoir in the upstream of Bhagirathi. The elevation-area-capacity curve for 2013 was plotted, as shown in Figure 4.

It was observed that the logarithmic plot between depth versus capacity followed a straight line, and the calculated value of $M$ (i.e. the inverse of the slope) was obtained as 2.433, which was within the range of $M=1.5-2.5$. Thus, based on Borland and Miller ${ }^{19}$ classification, the Tehri reservoir can be classified as Type III reservoir or hill type reservoir, as shown in Figure 5.

The NZE near the dam was found as $620 \mathrm{~m}$ in 2005 which was raised to $630 \mathrm{~m}$ in 2008. The NZE was then computed as $634.0 \mathrm{~m}$ by empirical area reduction method using the area design curves of type III reservoir. NZE from the 2013 hydrographic survey data was at $4 \mathrm{~m}$, which signified up to a $4 \mathrm{~m}$ bed level rise close to the dam due to the progressive accumulation of sediments inside the reservoir. Vertical distribution of sediment deposition (accumulated sediment volume as percent of total) is shown in Figure 6. The sedimentation in different zones of the reservoir, as observed from the zonal sediment distribution analysis indicated that zone VII and zone VIII which lie in Bhagirathi (23-44.8 km) would be the most vulnerable and contribute the maximum reduction of capacity in the reservoir as shown in Table 2.

\section{Empirical curve method}

The trap efficiency as per Brune's curve was estimated to be $96 \%$ (for $\mathrm{C} / \mathrm{I}=0.690501$ year), and the corresponding rate of siltation was estimated as $9.24 \mathrm{MCM} /$ year. The trap efficiency as per Churchill's curve turned out to be $93 \%$ when measured with capacity up to MDDL (for SI of reservoir $=4.80 \times 108 \mathrm{sec}^{2} / \mathrm{m}$ ) and showed an increase 
RESEARCH ARTICLES

Table 2. Sediment deposition at different zones of Tehri reservoir

\begin{tabular}{lcccc}
\hline Zone & $\begin{array}{c}\text { Capacity at FRL as per } \\
\text { 2008 survey (MCM) }\end{array}$ & $\begin{array}{c}\text { Capacity at FRL as per } \\
\text { 2013 survey (MCM) }\end{array}$ & $\begin{array}{c}\text { Reduction of } \\
\text { capacity (MCM) }\end{array}$ & $\begin{array}{c}\text { \% Reduction } \\
\text { of capacity }\end{array}$ \\
\hline I & 32.42 & 32.18 & 0.23 & 0.73 \\
II & 231.85 & 231.34 & 0.50 & 0.21 \\
III & 527.59 & 523.31 & 4.28 & 0.81 \\
IV & 982.45 & 975.91 & 6.54 & 0.66 \\
V & 896.60 & 893.80 & 2.80 & 0.31 \\
VI & 500.71 & 499.3 & 1.35 & 0.27 \\
VII & 280.05 & 276.15 & 3.89 & 1.39 \\
VIII & 75.79 & 73.77 & 2.02 & 2.66 \\
Total & 3527.50 & 3505.8 & 21.65 & 0.61 \\
\hline
\end{tabular}

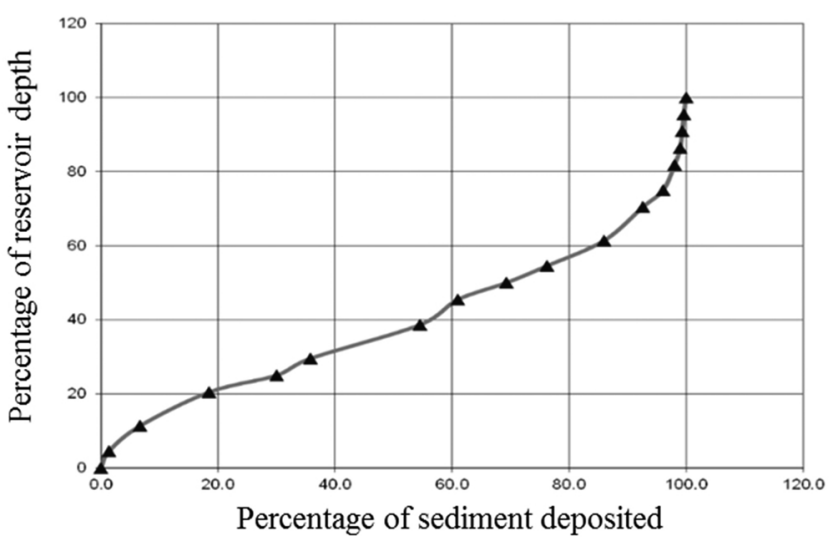

Figure 6. Percentage plot of depth versus deposition.

to $97 \%$ when measured with capacity up to FRL (for SI $=7.20 \times 10^{9} \mathrm{sec}^{2} / \mathrm{m}$ ). Thus Churchill's curve gives a better estimation of trap efficiency than Brune's curve; however, it is difficult to obtain the input data for calculating the sedimentation index $(\mathrm{SI})^{36}$.

\section{HEC-RAS hydrodynamic model}

The HEC-RAS model simulation showed a total loss in the reservoir capacity of $25.3 \mathrm{MCM}$ with an average of 5.07 MCM/year after the model ran for five years (20082013). The result fairly complied with the yearly rate of sedimentation of $5.33 \mathrm{MCM} /$ year, which was obtained with the hydrographic survey as shown in Table 1, with an error of $4.9 \%(\leq 10 \%)$. It was observed from the simulation that after suffering some retrogression in the upstream reaches, sediment accumulated mainly between 25 and $30 \mathrm{~km}$ reaches of Bhagirathi river as well as 16 and $25 \mathrm{~km}$ and 10 and $14 \mathrm{~km}$ reaches of Bhilangana river. This observation was supported by spatial velocity plots, and velocity in the reservoir decreased at $30 \mathrm{~km}$ of River Bhagirathi and also attained a lower value at $25 \mathrm{~km}$, causing the maximum deposition in the vicinity. The same phenomenon was observed in the River Bhilangana between 25 and $15 \mathrm{~km}$, causing maximum deposition. The changes in cross-sections for both the rivers in 100 years revealed considerable variation in the cross-sections of these reaches, which may cause large volumes of sediment deposition. The model results conform to the zonal distribution study carried out in hydrographic survey method. The deposition in cross-section of $29 \mathrm{~km}$ in Bhagirathi and $25 \mathrm{~km}$ in the Bhilangana respectively, from the axis of the dam, in 100 years are shown in Figure $7 a$ and $b$. The model also provided $L$-sections and $X$-sections for both the rivers at all cross-sections and the values were plotted for every 25 years till 100 years. Thus, the total deposition corresponds to $508 \mathrm{MCM}$ in the reservoir in 100 years, i.e. the rate of siltation is $5.08 \mathrm{MCM} /$ year (total loss of capacity in 108 years is $550.66 \mathrm{MCM}$ $(508+42.66 \mathrm{MCM}))$; which gives the total loss of MDDL capacity (916.209 MCM) of the reservoir in 180 years.

\section{SRS method}

The remotely sensed imageries were classified using FCC in the ERDAS-Imagine software. Delineating 18 September 2013, FCC image for finding water spread area in the ArcGIS toolbox is indicated in Figure 8.

The loss of storage between the lowest point (EL $751.15 \mathrm{~m}$ ) and the highest point (EL $824.7 \mathrm{~m}$ ) among the five cloud-free passes of 2013 was calculated from Table 3 as $46.06 \mathrm{MCM}$ since 2005, compared to the actual loss estimated from hydrographic survey as 42.6 MCM (36.6 MCM for same level).

The average estimated loss rate which was derived from the elevation-capacity curve obtained using SRS technique was found to be $5.7 \mathrm{MCM} /$ year, compared to an actual loss rate of 4.6 MCM/year between $751.2 \mathrm{~m}$ and $824.7 \mathrm{~m}$ elevation. However, the rates of siltation were in coherence with gross siltation rates of $5.33 \mathrm{MCM} /$ year. In agreement with this finding, Pandey et $a l^{27}$ have also found that the SRS method of reservoir sedimentation rate analysis overestimated the observed values. Therefore, it is suggested to use integrated approaches of hydrographic survey below MDDL, and multispectral 

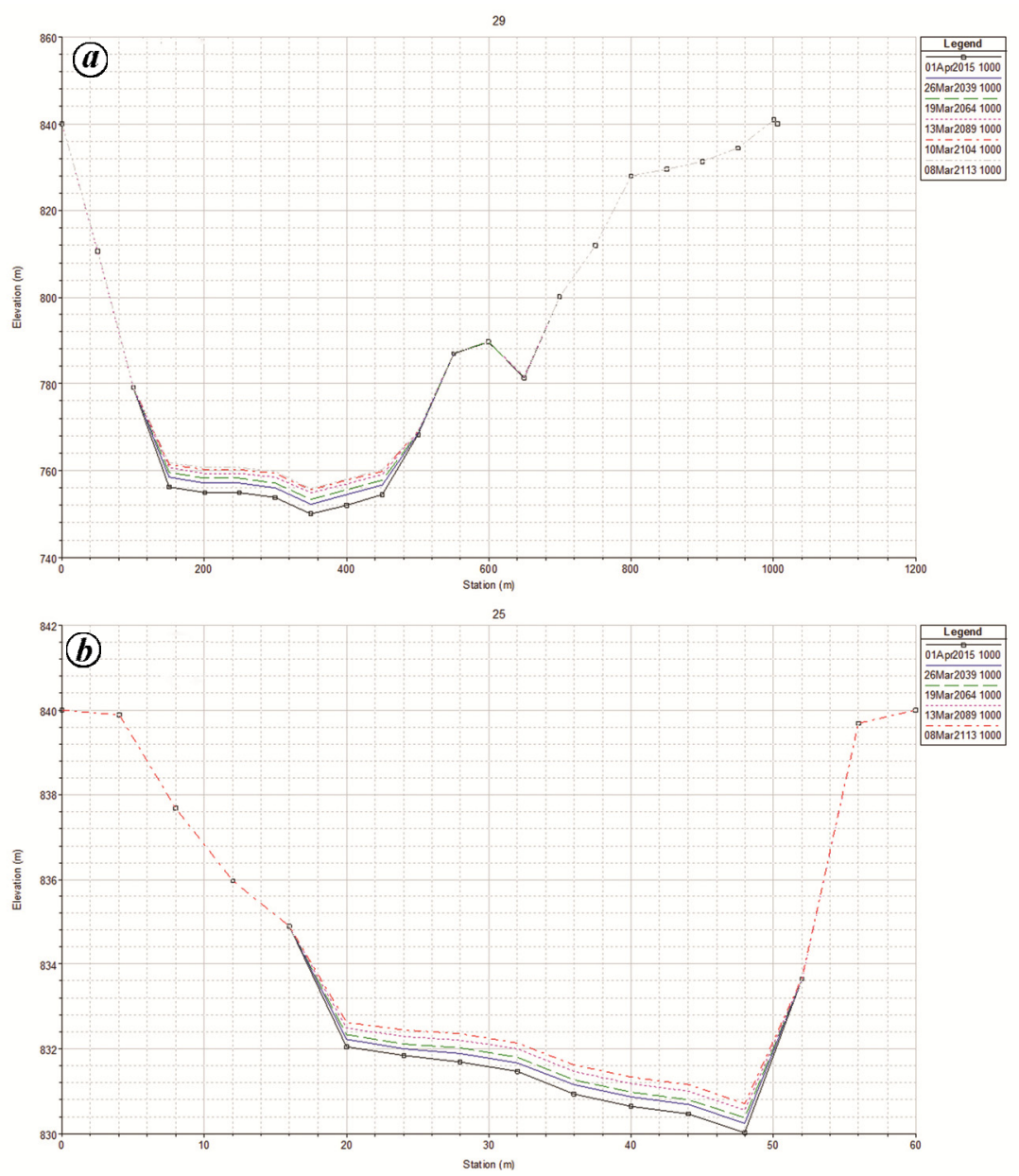

Figure 7. $\boldsymbol{a}$, Deposition at $29 \mathrm{~km}$ cross-section of River Bhagirathi in 100 years. $\boldsymbol{b}$, Deposition at $25 \mathrm{~km}$ cross-section of River Bhilangana in 100 years.
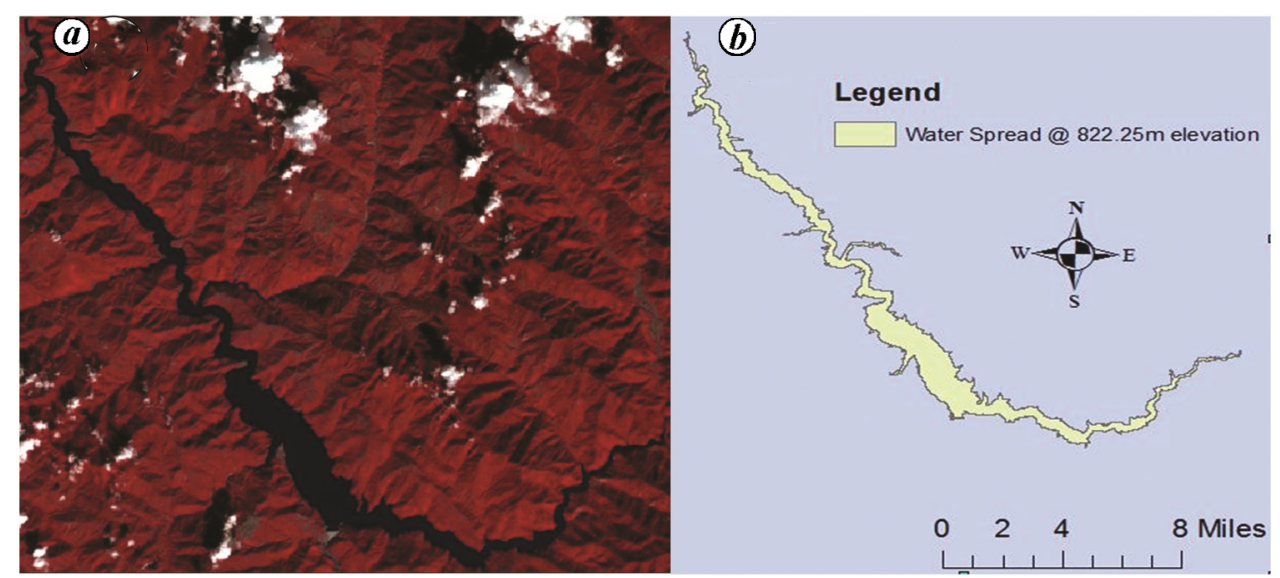

Figure 8. a, False-colour composites (FCC) Landsat 8 image of Tehri reservoir as of 18 September 2013. $\boldsymbol{b}$, Water spread as of 18 September 2013.

SRS analysis from MDDL to FRL for the accurate estimation of sedimentation.

\section{The useful life of a reservoir}

The useful life of a reservoir is an important design parameter of a reservoir, and in most countries, full life is said to have arrived, when half of the total capacity of the reservoir is depleted ${ }^{37}$. In the present study, useful life was calculated based on the results obtained in the previous sections on the rate of siltation for filling MDDL and for filling 70\% FRL. It can be seen in Figure 9 that the useful life of the reservoir obtained from HECRAS model and SRS method, are closely related with 
RESEARCH ARTICLES

Table 3. Water spread and volume computation

\begin{tabular}{|c|c|c|c|c|c|c|c|c|c|c|}
\hline $\begin{array}{l}\text { Date of } \\
\text { satellite } \\
\text { data }\end{array}$ & Elevation & $\begin{array}{l}\text { Elevation } \\
\text { difference }\end{array}$ & $\begin{array}{l}\text { Observed } \\
\text { area } 2013\end{array}$ & $\begin{array}{c}\text { Revised } \\
\text { surface area } \\
\text { using RS }\end{array}$ & $\begin{array}{l}\text { Observed } \\
\text { live storage } \\
\text { volume }\end{array}$ & $\begin{array}{c}\text { Revised live } \\
\text { storage volume } \\
\text { using RS }\end{array}$ & $\begin{array}{c}\text { Observed } \\
\text { cumulative } \\
\text { volume }\end{array}$ & $\begin{array}{c}\text { Revised } \\
\text { cumulative } \\
\text { volume } \\
\text { using RS }\end{array}$ & $\begin{array}{l}\text { Observed } \\
\text { volume } \\
2005\end{array}$ & $\begin{array}{c}\text { Revised } \\
\text { cumulative } \\
\text { volume } 2005\end{array}$ \\
\hline dd-mm-yy & (m) & (m) & $\left(\mathrm{Mm}^{2}\right)$ & $\left(\mathrm{Mm}^{2}\right)$ & $\left(\mathrm{Mm}^{3}\right)$ & $\left(\mathrm{Mm}^{3}\right)$ & $\left(\mathrm{Mm}^{3}\right)$ & $\left(\mathrm{Mm}^{3}\right)$ & $\left(\mathrm{Mm}^{3}\right)$ & $\left(\mathrm{Mm}^{3}\right)$ \\
\hline MDDL & 740 & 0 & 18.03 & & & & 907.45 & & 18.35 & 916.2 \\
\hline $13-05-13$ & 757.2 & 6.05 & 21.42 & 22.05 & 126.7 & 129.26 & 1229.8 & 1259.55 & 21.75 & 1257.21 \\
\hline $30-06-13$ & 780.7 & 23.55 & 26.76 & 26.99 & 584.4 & 576.56 & 1814.2 & 1836.11 & 27.28 & 1843.8 \\
\hline $18-09-13$ & 822.2 & 41.5 & 39.22 & 38.8 & 1365.5 & 1357.8 & 3179.6 & 3194 & 40.75 & 3211.83 \\
\hline $20-10-13$ & 824.7 & 2.45 & 40.15 & 39.2 & 119.3 & 95.56 & 3299 & 3289.56 & 41.78 & 3335.63 \\
\hline FRL & 830 & 5.3 & 41.97 & & 206.8 & & 3505.8 & & 43.37 & 3548.51 \\
\hline
\end{tabular}

RS, Remote sensing data.

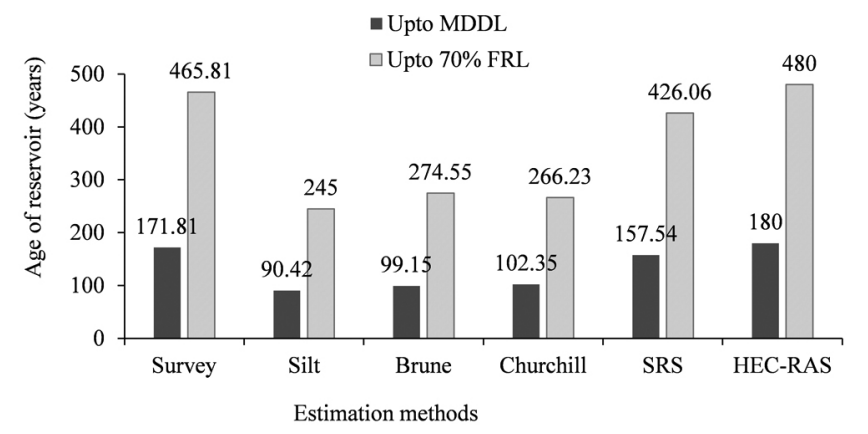

Figure 9. Estimated useful life of Tehri reservoir from different methods.

hydrographic survey estimation which validated both these techniques. The empirical methods were found to be more suitable for normally ponded reservoirs lying in plains where cascading reservoirs are not present. The HEC-RAS model and SRS method are closer in depicting the physical condition and can be employed as alternative methods of a hydrographic survey. Issa et $a .^{38}$ also carried out a similar study on the useful life of Mosul reservoir in Iraq, using the bathymetric survey and analytical approach and found value of the 125 years.

\section{Conclusion}

In this paper, integrated approaches of hydrographic survey analysis, trap efficiency methods, HEC-RAS modelling, and SRS method were used for the estimation of sedimentation rate and also for the calculation of the useful life of the Tehri reservoir. The hydrographic survey revealed that the reservoir was losing its capacity at a rate of $5.33 \mathrm{MCM} / \mathrm{year}$, while the model estimated the average siltation rate of $5.07 \mathrm{MCM} /$ year and $5.75 \mathrm{MCM} /$ year as per the SRS technique. The capacity of the reservoir lost by $1.3 \%$ in eight years from 2005 to 2013 , which is $0.16 \%$ per year from the active storage capacity. This shows that the Tehri reservoir performance is better than the country's average annual siltation rates.
Based on the sediment vertical distribution study, the reservoir is classified as type III (or hill type) as per the empirical area reduction method with a value of ' $\mathrm{M}$ ' as 2.24 . Moreover, the NZE lies at $634 \mathrm{~m}$, which indicated a progressive loss of the dead storage capacity. Churchill's and Brune's methods overestimated the rates of siltation, and thus, they would not be suitable for the Tehri reservoir. The maximum deposition and erosion were observed in zones VII and VIII (23-42 km) of Bhagirathi and throughout zone I and II (10-25 km) of Bhilangana, as per HEC-RAS model results and hydrographic survey analysis. The useful life of the reservoir was well approximated by the HEC-RAS model as 180 years, whereas it was 160 years by SRS techniques and 170 years by survey method. The SRS technique can be used as a substitute for intermediate surveys since surveying is an expensive and time-consuming exercise. However, this technique can only be used between MDDL and FRL. In general, it is suggested to use integrated approaches of hydrographic survey below MDDL, SRS analysis from MDDL to FRL, and hydrodynamic modelling methods and empirical curve for a more appropriate estimation to help the decision/policy makers for proper sediment management. In the present study, a one-dimensional (1D) river model analysis was developed, with the availability of detailed observed data. However, it is suggested to use $2 \mathrm{D} / 3 \mathrm{D}$ models particularly in the downstream region to depict a better computation efficiency. The remote sensing data presents an approximate estimation due to limitations of higher resolution satellite images. Therefore, the availability of higher resolution imageries, including light detection and ranging technology, would improve the SRS application for accurate estimation of sedimentation process.

Disclosure statement: No potential conflict of interest was reported by the authors.

1. Sumi, T. and Hirose, T., Accumulation of sediment in reservoirs. In Water Storage, Transport, and Distribution-Encyclopedia of 
Life Support Systems (ed. Takahasi, Y.), EOLSS Publishers, Oxford, UK, 2009, pp. 224-252.

2. Kondolf, G. M. et al., Sustainable sediment management in reservoirs and regulated rivers: experiences from five continents. Earth's Future, 2014, 2(5), 256-280.

3. Wang, H. W. and Kondolf, G. M., Upstream sediment-control dams: five decades of experience in the rapidly eroding Dahan River Basin, Taiwan. J. Am. Water Resour. Assoc., 2014, 50(3), 735-747; doi:10.1111/jawr.12141.

4. Luis, J., Sidek, L. M. and Jajarmizadeh, M., Impact of sedimentation hazard at Jor Reservoir, Batang Padang hydroelectric scheme in Malaysia. In IOP Conference Series: Earth and Environmental Science, IOP Publishing Ltd, UK, 2016, vol. 32, no. 1, p. 012030; doi:10.1088/1755-1315/32/1/012030.

5. Graf, W. H., The hydraulics of reservoir sedimentation. International Water Power Dam Construction, 1983, 35(4), 45-52.

6. Garcia, M. H., Sediment transport and morphodynamics. In Sedimentation Engineering: Processes, Measurements, Modelling, and Practice (ed. Garcia, M.), ASCE Manuals and Reports on Engineering Practice No. 110. American Society of Civil Engineers, Reston, VA, 2008, pp. 21-164.

7. Morris, G. L. and Fan, J., Reservoir Sedimentation Handbook: Design and Management of Dams Reservoirs, and Watershed for Sustainable Use, McGraw-Hill Book Company, New York, USA; 2010; http://reservoirsedimentation.com.

8. Fiock, L. R., Records of silt carried by the Rio Grande and its accumulation in Elephant Butte Reservoir. Eos Trans. Am. Geophys. Union, 1934, 15(2), 468-473.

9. Annandale, G., Quenching the Thirst: Sustainable Water Supply and Climate Change, CreateSpace Independent Publishing Platform, North Charleston, SC, USA, 2013.

10. UNESCO, Water in a Changing World. The United Nations World Water Development Report 3, World Water Assessment Programme, Routledge, 2012, p. 190.

11. Central Water Commission (CWC), Compendium on silting of reservoirs in India. Ministry of Water Resources, Watershed and Reservoir Sedimentation Directorate, New Delhi, India. 2015.

12. MoWR, Storage Status of 91 Major Reservoirs of the Country as on 5 November 2015. Press Information Bureau, Govt. of India, Ministry of Water Resources (MoWR), New Delhi, India, 2015; http://pib.nic.in/newsite/PrintRelease.aspx?relid=130237 (accessed on May 2016).

13. Merina, N. R., Sashikkumar, M. C., Rizvana, N. and Adlin, R., Sedimentation study in a reservoir using remote sensing technique. Appl. Ecol. Environ. Res., 2016, 14(4), 296-304.

14. Eakin, H. M., Instructions for reservoir sedimentation surveys, in silting of reservoirs. Technical Report, US Department of Agriculture, Technical Bulletin, 1939.

15. Brown, C. B., Discussion of Sedimentation in reservoirs, by J. Witzig. In Proceedings of the American Society of Civil Engineers, 1943, 69(6), 1493-1500.

16. Churchill, M. A., Discussion of analyses and use of reservoir sedimentation data by L.C. Gottschalk. In Proceedings of the Federal Inter-agency Sedimentation conference, Denver, USA, 1948, pp. 139-140.

17. Brune, G. M., Trap efficiency of reservoirs. Eos Trans., Am. Geophys. Union, 1953, 34(3), 407-418; doi:10.1029/TR034i003p00407.

18. Cristofano, E. A., Area increment method for distributing sediment in a reservoir. US Bureau of Reclamation, Albuquerque, New Mexico, 1953.

19. Borland, W. M. and Miller, C. R., Distribution of sediment in large reservoir. J. Hydraul. Div., 1958, 84(2), 1-18.

20. Solomonson, V. V., Remote sensing applications in water resources. In Third Earth Resources Technology Symposium, Washington DC, USA, 1973, pp. 10-14.
21. Smith, S. E., Mancy, K. H. and Latif, A. F. A., The application of remote sensing techniques towards the management of the Aswan high dam reservoir. In 14th International Symposium on Remote Sensing of Environment, San Jose, Costa Rica, 1980, pp. 12971307.

22. Vemu, S. and Udayabhaskar, P., An integrated approach for prioritization of reservoir catchment using remote sensing and geographic information system techniques. Geocarto Int., 2010, 25(2), 149-168.

23. Goel, M. K., Jain, S. K. and Agarwal, P. K., Assessment of sediment deposition rate in Bargi Reservoir using digital image processing. Hydrol. Sci. J., 2002, 47(S1), S81-S92.

24. Keys, T. A. and Scott, D. T., Monitoring volumetric fluctuations in tropical lakes and reservoirs using satellite remote sensing. Lake Reserv. Manage., 2018, 34(2), 154-166.

25. Jagalingam, P., Akshaya, B. J. and Hegde, A. V., Bathymetry Mapping Using Landsat 8 Satellite Imagery. Procedia Eng., 2015, 116, 560-566; doi:10.1016/j.proeng.2015.08.326.

26. Jain, S. K., Singh, P. and Seth, S. M., Assessment of sedimentation in Bhakra reservoir in the western Himalayan region using remotely sensed data. Hydrolog. Sci. J., 2002, 47(2), 203-212; doi:10.1080/02626660209492924.

27. Pandey, A., Chaube, U. C., Mishra, S. K. and Kumar, D., Assessment of reservoir sedimentation using remote sensing and recommendations for desilting Patratu Reservoir, India. Hydrol. Sci. J., 2016, 61(4), 711-718.

28. Koomullil, D. S., Chaube, U. C. and Pandey, A., Revisiting the useful life computation of Gobindsagar (Bhakra) reservoir. ISH J. Hydraul. Eng., 2016, 22(2), 115-123; doi:10.1080/09715010. 2015.1084600

29. Vishnoi, R. K. and Govil, R., Sedimentation and life of the reservoir. Water Energ. Int., 2007, 64(1), 99-107.

30. Brunner, G. W., Hydraulic Reference Manual, US Army Corps of Engineers, Hydrologic Engineering Center, Davis, CA, 2010.

31. USACE, HEC-RAS River Analysis System Hydraulic Reference Manual, Ver. 5.0, 2016.

32. Chow, V. T., Open-Channel Hydraulics, McGraw-Hill, New York, 1959, vol. 1, p. 680.

33. Ackers, P. and White, W. R., Sediment transport: new approach and analysis. J. Hydraulics Div., 1973, 99 (hy11).

34. Barsi, J., Lee, K., Kvaran, G., Markham, B. and Pedelty, J., The spectral response of the Landsat- 8 operational land imager. Remote Sens., 2014, 6(10), 10232-10251.

35. IS Manual 13665, Sedimentation in Reservoirs - Method of Measurement, New Delhi, India, 1993.

36. Verstraeten, G. and Poesen, J., Estimating trap efficiency of small reservoirs and ponds: methods and implications for the assessment of sediment yield. Prog. Phys. Geog., 2000, 24(2), 219-251.

37. Garg, V. and Jothiprakash, V., Estimation of useful life of a reservoir using sediment trap efficiency. J. Spat. Hydrol., 2008, 8(2), 1-14.

38. Issa, I. E., Al-Ansari, N., Sherwany, G. and Knutsson, S., Sedimentation processes and useful life of Mosul dam reservoir, Iraq. Engineering, 2013, 5(10), 779-784; https://doi.org/10.4236/eng. 2013.510094.

ACKNOWLEDGEMENTS. The authors would like to thank Tehri Hydro Development Corporation (THDC), Central Water Commission of India (CWC), and the United States Geological Survey (USGS) for providing the data. The authors are also thankful to the anonymous reviewer for constructive comments and suggestions which substantially improved this paper.

Received 8 January 2019; revised accepted 26 September 2019

doi: $10.18520 / \mathrm{cs} / \mathrm{v} 118 / \mathrm{i} 3 / 411-420$ 